\title{
SPECIAL CHARACTERISTICS OF MARKET SUPPLY FORMATION IN THE HOUSING DEVELOPMENT SECTOR AND RESIDENTIAL BUILDINGS RECONSTRUCTION UNDER THE PRESENT-DAY CONDITIONS IN RUSSIA
}

\author{
Larisa Selyutina $^{1}$, Natalia Vasileva ${ }^{2}$, Tatyana Maleeva ${ }^{3}$, Natalya Frolova ${ }^{4}$
}

\begin{abstract}
It is necessary to understand the housing market situation for selecting strategic measures that are able to ensure the balanced state of market supply and demand. This task is very relevant in the field of housing stock development and reconstruction in Russia. The up-to-date aspect of this issue has been investigated in this paper, and it is marked by the particular characteristics of intercommunication of the processes of supply generation for the purpose of satisfaction of demands for reconstruction and building activities projects in the housing sector and investment supply introduced into the investment market. This paper directs attention to the necessity of expanding the forms of housing needs satisfaction in order to increase housing affordability. This research is of practical importance and is intended to improve the performance of the modern housing reproduction market in Russia owing to the further development of the market mechanisms and tools, which ensure the reliability of housing development and housing stock reconstruction investments in line with people's investment and consumer demands.
\end{abstract}

JEL Classification Numbers: R31, M21, DOI: 10.12955/cbup.v7.1375

Keywords: reconstruction, housing construction, investment proposal, social housing policy.

\section{Introduction}

Integration of reconstruction and building activities into a single investment and building city complex generates a peculiar approach to the identification of market supply characterized by a symbiosis of the following aspects: supply evolution in order to satisfy consumer demand for real property objects and the formation of the investment supply for investment market positioning.

Disposing of the entire recreated building by means of its sale to a single owner (a person or a company) is wide-spread in international practices (Ball, 2003; Epple et al., 2010). A building owner either uses it for personal needs or makes arrangements for renting certain dwelling units. It should be kept in mind that satisfaction of housing needs of the most countries' common population is realized at the expense of housing rent (Early, 2000; Hankinson, 2018; Maleeva, 2013; Bulgakova \& Selyutina, 2018). In this context, such a method of disposing of the reconstructed housing stock appears to be quite natural.

In Russia, housing rent as a phenomenon is just actually in progress. The primary way to satisfy Russian people's housing needs was and remains the usage of a separate apartment in a tenement house. Furthermore, apartments implemented among the end-users are the most common form of supply brought to the housing market (Bulgakova, 2014).

The process of formation of this market supply form in reconstruction and building area encounters a series of restrictions. The first one comes from the structural engineering and architectural planning features of the housing buildings subject to refurbishment and reconstruction. Such buildings include a definitive grid of bearing walls that precludes designers from using all planning concepts in what they deem to be rational.

For another thing, a structure of buildings under reconstruction itself (especially, a host of yard outhouses) imposes a set of constraints necessitating observation of sanitary regulations, rules of internal transportation and pedestrian routes, amenities, etc. These conditions make an impact on the characteristics of apartments located in residential houses under refurbishment. Generally, they contain more multi-room apartments (this is dictated by the technical and economic expediency of using the gross building area), fewer apartments consisting of two or three rooms, and almost no oneroomed apartments.

These characteristics determine the possible directions of implementation of such apartments. They may be intended for consumption by individuals with a high level of needs and high solvency. In reconstructed housing stock, not only a price of apartments being brought to the market is high, which

\footnotetext{
${ }^{1}$ Emperor Alexander I St. Petersburg State Transport University, Saint-Petersburg, Russia, ya.slarisa@ya.ru

${ }^{2}$ Saint-Petersburg State University of Economics, Saint-Petersburg, Russia, vasileva.n@ unecon.ru

${ }^{3}$ Pushkin Leningrad State University, Saint-Petersburg, Russia, info@ maleeva.spb.ru

${ }^{4}$ Pushkin Leningrad State University, Saint-Petersburg, Russia, frolova.molla@gmail.com
} 
results from the large volume of their total area, but also the price of one square meter. It is formed under the influence of many factors and, predominantly, the factor of an object's location in the urban environment (Bulgakova \& Selyutina, 2018). In this regard, reconstructed housing buildings have clear benefits, as they are usually located in the finest districts and in the economically most valuable areas.

The purpose of this study is to substantiate the author's approach to the formation of a market supply in the field of construction and reconstruction of the housing stock, the main feature of which is an interconnected consideration of two aspects: the formation of supply to meet the demand for objects of reconstruction and construction activity in the housing sector and the investment offer that is output on the investment market.

\section{Literature review}

The current state of the housing market can be characterized by several key parameters: supply in the housing market; solvent demand; existing mechanisms for the purchase (sale) of housing; factors affecting the formation of market prices; the duration of the investment cycle; legal support.

In Russian and foreign literature there are a large number of works devoted to the study of the housing market, while the range of issues and problems under consideration is very wide. Conventionally, they can be divided into three groups. The first group of studies is those that are devoted to analyzing the housing market in general and studying the dynamics of key indicators. Most of the work is devoted to the construction of price indices, which are the main indicators of the dynamics of the housing market (Bourassa et al., 2013; Sidorovykh, 2015; Sinai, 2010; Wu et al., 2014). The construction of price indices has a number of practical uses, such as forecasting the level of prices in the residential real estate market, assessing changes in the probability of mortgage defaults, measuring the level of housing affordability, etc.

The second group of works is aimed at studying demand. Using the model of adaptive expectations allows you to study the behavior of buyers, namely, their perception of the current market situation and expectations regarding future price movements, which influences the decision to purchase residential real estate. Ultimately, consumer behavior partly determines the average price level in the market, the level of demand, and the general state of the market (Hui \& Wang, 2014). In addition, one of the most common trends in the study of demand in the real estate market is the determination of the optimal time for real estate purchase (Arbel et al., 2009). The study of this problem not only gives an idea of the behavior of buyers, but also has an important practical application. However, the main problem remains the implementation of a more accurate assessment of demand. A number of interesting studies are devoted to this problem (Khachatryan, 1998; Konstantinovsky, 2000), in which the issues of forecasting housing demand are modeled.

Finally, the third group of studies is based on the study of the supply side. Three main topics can be distinguished here: determining the relationship between asking price, selling price and the duration of the sale of an apartment (Anglin et al., 2003; Ball et al., 2010; Phang et al., 2010); identifying the effect of vendor characteristics on prices and sales duration (Glaeser \& Gyourko, 2018; Knight, 2002; Gyourko \& Saiz, 2006; Murphy, 2018); and the selection of the best option for housing supply in the market (Arnold, 1999; Kornilova, 2000; Yishen, 2018; Pyankova, 1997).

The reconstruction and construction market is an integral part of the single residential real estate market. It aggregates many completed and prepared for operation objects. At the same time, in the investment and construction complex there is an expanded aggregate of residential buildings that need to be reconstructed. Such objects are represented on the market as potential investment proposals.

There are many studies devoted to the study of demand in the market of reconstructive construction products (Pasechnyuk, 2014; Buzyrev, 2013; Maleeva, 2013; Vasileva, 2003), while the supply side is studied to a much lesser extent.

The main conclusion on the analysis and development of market relations in the field of residential real estate is that some progress has been made in the formation and development of the housing market. At the same time, the analysis made it possible to identify the characteristic features of the housing market sectors, the possibilities of their expansion and forecasting, as well as the creation of the market environment necessary to meet the housing needs of the population. 


\section{Materials and Methods}

In conducting the study, a set of complementary methods was used: information retrieval, comparative method, analysis and systematization of scientific publications on the problem under study, etc. As sources of information for this study, we used the works of Russian and foreign economic scientists on important aspects of the problems of managing the construction and reconstruction business in the housing sector.

The reconstructive housing market, in our opinion, should be considered as a special market space in which natural or legal persons who want to acquire reconstructed or capitally repaired residential objects act as demand carriers, and as a proposal - residential buildings, their sections and apartments that have been overhauled or reconstructed and prepared for implementation.

The possibility of the arrangement of mainly multi-room apartments in reconstructed housing stock should be taken into account when building city-planning models. For example, it is well-known that in a number of major cities (Moscow, St. Petersburg), where an old stock share is the largest, for years and years there was a sustained deficit for one- and two-room apartments. At the same time, a number of apartments consisting of four and more rooms typically exceeded the socially desired level.

Under modern conditions, requirements for a residential structure of accommodation introduced to the market have changed significantly (Maleeva \& Selyutina, 2018). These changes are determined by several processes:

- differentiation of consumers by solvency level;

- the development of consumers' preferences (especially among consumers with high and middle levels of income);

- contraction of social housing construction volume;

- the appearance in the recent years of a diverse market supply owing to new construction.

It seems to be impossible to categorically assess the aggregate exposure of these processes. Consistent assessments of the nature and structure of consumer preferences can be obtained only in the course of large-scale marketing research.

The second restriction as pertaining to reconstruction and building activities development deal with the possibility of a sale of accommodation after the necessary major repairs, modernization and reconstruction works have been completed. When a building is placed under total renovation, its residents shall move. This can be temporary, through the use of temporary public housing more permanent. In the case of temporary relocation, tenants of reconstructed houses are entitled to settle in apartments previously occupied by them after the whole range of works is completed. In the case of permanent relocation of tenants, they receive the equivalent housing in other buildings (districts) of the city. There are certain organizational and administrative mechanisms governing resettlement of the tenants of buildings under renovation (Buzyrev, 2013). In such event, only a part of apartments is overhauled and reconstructed houses are brought to the market as an independent supply. This sets limits on the possibility of building adequate market relations in reconstruction and building area.

Premises in residential buildings, which are advisable to be used for non-residential needs - the premises located on the entry levels of buildings, attic rooms etc., also act as a supply. They represent pieces of commercial real estate, which are traded in the relevant market. When forming pieces of commercial real estate as a part of residential objects, the following recommendations should be adhered to:

- arrange for autonomous access to the dwelling and non-dwelling units;

- create a background for coordinated infrastructure provision of such pieces;

- ensure compliance with the segment structure of consumers of dwelling and non-dwelling objects.

\section{Results and Discussion}

Reconstruction and building products, as a real estate, are formed as a result of the fulfillment of a long-term manufacturing cycle (several months, a year, several years), which is associated in the market conditions with increased financial risks (Egorova, 2009).

The attractiveness of specific investment proposals cannot be evaluated by just one, even a highly qualified specialist. It requires the involvement of a team of specialists who are masters of consulting 
group technologies tools and adequate organizational support. In the developed market economies, there is a chain of specialized consulting firms evaluating investment projects, including but not limited to in the field of residential stock construction and reconstruction (Cohen, 2001). Among the specialists of such firms are specialists in the field of technique and technology of reconstruction and building activity, economy and finance, design and urban planning. The coexistence of different competencies makes it possible to give sufficiently reasonable investment estimates.

Immediately after a conceptual investment proposal is developed, it is necessary to proceed with the creation of a database of potential investors who may be interested in one and another supply. Simultaneously, pre-design studies are carried out, which represent an initial stage in the formation of integral characteristics - residential building or complex reconstruction project. Potential investors' database development requires the use of tools of monitoring, which provides for arranging continuous monitoring and analysis of the situation by means of the fixed indicators. The most expedient is the creation of a complex system of economic monitoring used by the management entity of the reconstruction and building area. Such economic monitoring reflects a set of indicators characterizing the state and prospects of development of the market environment, and information about potential investors is presented in it not separately but in the relationship with other critical information.

Prospective investors, as well as the intended users of reconstructed facilities, receive investment and sales quotes generated on the basis of pre-design developments. This involves not only a formal sending of the offers, but dealing with the most promising contingent of investors (and possible users), aimed not only at taking into account investors' wishes but also to provide evidence of reconstruction project effectiveness. Upon completion of this phase and obtaining satisfactory results, investment development should continue. Investors often advance counter-claims that need to be assessed and, following such an assessment, accepted or rejected using the reasoned arguments. In such way requirements and interests of the various parties involved in reconstruction and building process, with reference to which the design task is formed, are coordinated.

It is important to stress that coordination procedures are beyond the scope of relationships between reconstruction and building activities investors and management entities. Reconstruction project acting as an investment offer must be agreed with the city-planning regulation, sanitary supervision, nature protection, fire safety, etc. authorities. Fig. 1 shows the algorithm of investment proposal formation process in reconstruction and building area. Formation of the investment offer should end with an evaluation of its final outcomes and socio-economic efficacy.

In the modern context, the reconstruction and building activities management system encounters another vital problem. It necessitates revolutionary transformations of residential buildings erected in the 50-60s by the methods of prefabricated construction. The principal foundations of its solution are based on the use of market mechanisms delivering harmony between supply and demand for prefabricated construction facilities (Vasileva, 2003).

The development of social housing construction plays an important role in the formation of market supply in the modern housing sector structure. To date, a recession of the level of provision with social housing, aging of existing infrastructure and its non-conformity with the current population composition becomes even more relevant for Russia in general and its regions in particular (Evseeva et. al., 2015).

Limited financial resources allocated for solving citizens' housing issues, the need for accurate budget allocation and new economic conditions, trends and consistent patterns require formulation of the other principles and methods of investing in social housing construction programs.

It is impossible to implement programs of housing sector modernization, create a favorable investment climate, implement structural reforms and responsible housing policy without competent investment management. Only by having provided all segments of the population with affordable and comfortable housing, authorities will become truly effective, economic growth will be possible in the regions and throughout the country (Rakova et. al., 2015). This principle works the other way around - improving the quality of people's lives is also impossible without economic growth of the region, so even when developing social housing construction programs, its economic efficiency should be also kept in mind.

In 1921, in F.H. Knight's "Risk, Uncertainty, and Profit", the first qualitative analysis of probabilitytheoretical mathematical methods of influence of risk events on the project outcome was conducted 
(Knight, 1921). G. Markovits' portfolio theory, which allows choosing investment projects from the standpoint of risk and profitability is relevant for the set-up of an investment portfolio (Markowitz, 1987). According to some Russian scientists (Egorova et al., 2017), the investment portfolio and investment program concepts are very close to each other. At the same time, scientists call attention to the fact that the investment portfolio represents a certain totality of projects, which an investor considers and then decides on the implementation of some of them, and a recommended totality itself is called an investment program, for which it is also considered reasonable to use an optimal portfolio model for the selection of investment projects too (Selyutina, 2018).

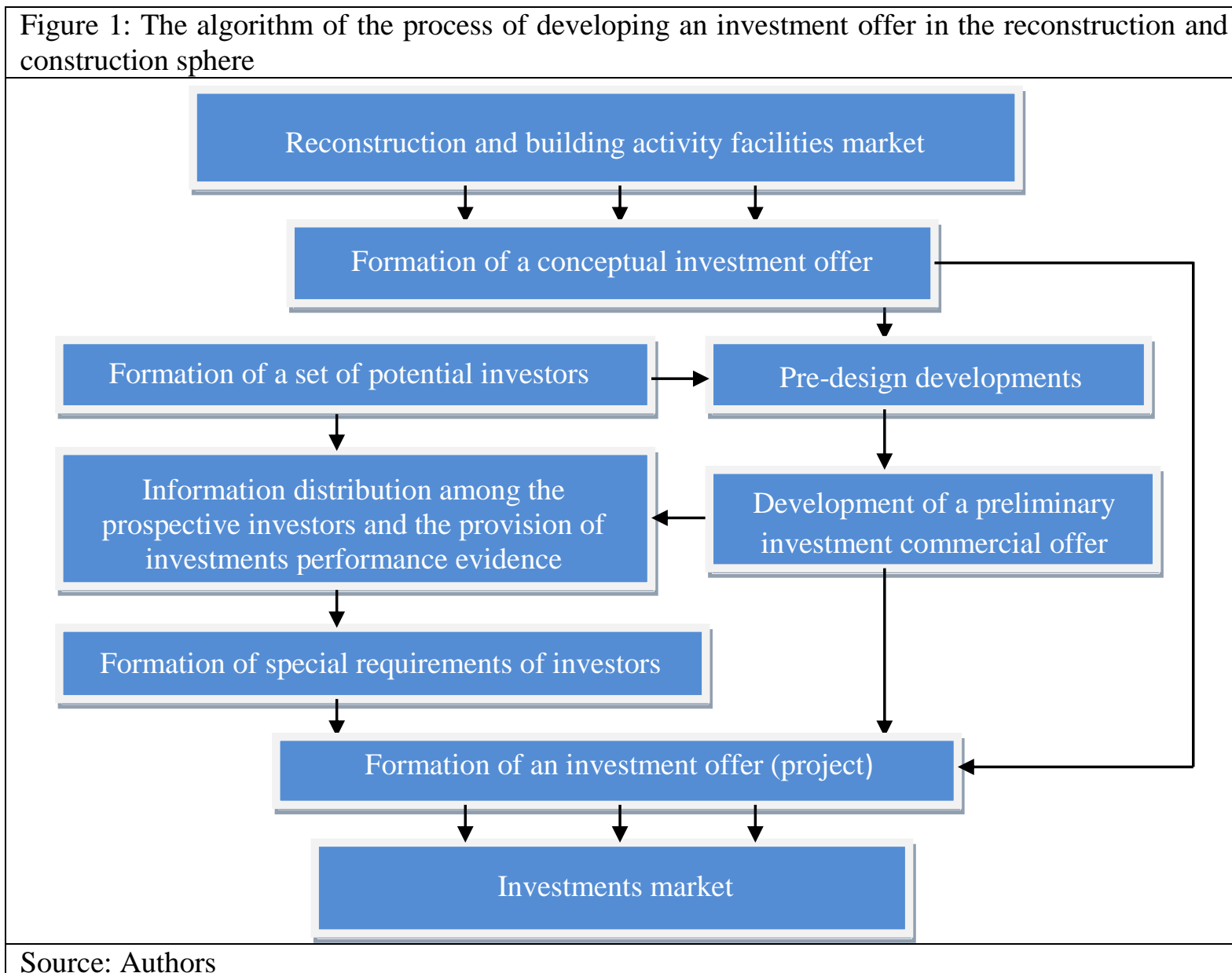

The said methods are actively used during the formation of commercial investment programs in various modifications, and various non-standard solutions of asset allocation are also broadly published (Merton, 1969). However, despite all the transparency and prospects of classical investment theory, it is not applicable to social projects and programs. Social housing construction investment programs are not developed on the basis of the invested assets return, so an alternative way of their optimization should be elaborated.

Typically, investments appraisal is associated with cost and benefits comparison. There are no doubts that existing methodological developments provide the basis for appraisal of investment projects of social housing construction, but its economic results are not as obvious and important as social.

\section{Conclusion}

In accordance with the foregoing, it follows that an understanding of the situation on the housing market is necessary for the selection of strategic measures that can ensure the formation of market supply in the reconstruction and construction sector. The development of a strategy for regulating market processes in this area, in our opinion, should include the following components:

- analysis of the housing market and forecasting its development;

- improvement of the legal framework;

- implementation of effective taxation; 
- stimulating the development of the housing market infrastructure;

- the implementation of an investment regulation system to enhance the reconstruction and construction activities and facilitate the flow of financial resources;

- the implementation of a progressive housing loan system, incl. mortgage lending;

- planning for extra budgetary sources of housing finance;

- social targeted support for low-income groups of the population.

However, due to the outlined saturation of some of the market, it is advisable to speed up the introduction of a new system of distribution of city apartments - rent of municipal housing and introduce registration of tenure and use rights.

In this case, the main public policy in reconstruction and construction area development represents measures for promoting investment offers in the real estate market. Generally, the implementation of social housing construction investment programs is a complex multi-stage process, one of the key stages of which is the selection of the most effective projects within the framework of an investment program. This need is particularly evident in Saint Petersburg, where a social housing shortage is particularly acute. In support of the investment offer, it is necessary to create attractive conditions for housing developers by means of, inter alia, accessible financing for the construction industry.

\section{References}

Anglin, P., Rutherford, R. \& Springer, T. (2003). The trade-off between the selling price of residential properties and timeon-the-market: the impact of price setting. Journal of Real Estate Finance and Economics, 26(1), 95-111.

Arbel, Y., Ben-Shahar, D. \& Sulganik, E. (2009). Mean reversion and momentum: another look at the price-volume correlation in the real estate market. Journal of Real Estate Finance and Economics, 39, 316-335.

Ball, M. (2003). Markets and the structure of the housebuilding industry: an international perspective. Urban Studies, 40, 897-916.

Ball, M., Meen, G. \& Nygaard, C. (2010). Housing supply price elasticity's revisited: evidence from international, national, local and company data. Journal of Housing Economics, 19(4), 255-268.

Bourassa, S., Cantoni, E. \& Hoesli, M. (2013). Robust repeat sales indexes. Real Estate Economics, 41(3), 517-541.

Bulgakova, K. (2014). Development of nonprofit housing as a method of forming an affordable and comfortable accommodation in Saint Petersburg. Journal Theory and practice of social development, 1, 374-376.

Bulgakova, K. \& Selyutina, L. (2018). Basics of investment projects selection for the implementation of regional investment programs in the sphere of social house building. Espacios, 39(26).

Buzyrev, V.V. (2013). The Housing problem and its solution in modern conditions. St. Petersburg: Saint-Petersburg State University of Economics.

Cohen, W. (2001). How to make it big as a consultant. New York: Amacom Publ.

Early, D. (2000). Rent control, rental housing supply, and the distribution of tenant benefits. Journal of Urban Economics, 48(2), 185-204.

Egorova, M. (2009). Financial aspect of effective management theory. Society. Environment. Development (Terra Humana), $3(12), 11-17$

Egorova, M., Bulgakova, K. \& Selyutina, L. (2017). Modelling of investment processes in the sphere of social house building. International Conference Proceedings 2017 - Innovations in science and education. Central Bohemia University. 67-72.

Epple, D., Gordon, B. \& Sieg H. (2010). A New Approach to Estimating the Production Function for Housing. The American Economic Review, 100(3), 905-924.

Evseeva, E.I., Martynova, A.V. \& Nikolyuk, E.S. (2015). Social housing construction in Russia: reality and development prospects. Science Review, 21, 218-220.

Glaeser, E., Gyourko, J. (2018). The economic implications of housing supply. Journal of Economic Perspectives, $32(1), 3-$ 30.

Gyourko, J., Saiz, A. (2006). Construction costs and the supply of housing structure. Journal of Regional Science, 46, 66180.

Hankinson, M. (2018). When do renters behave like homeowners? High rent, price anxiety and NIMBYism. American political science review, 112(03), 473-493.

Hui, Ch M, Wang, Z. (2014). Market sentiment in private housing market. Habitat International, 44, 375-385.

Khachatryan, S. (1998). Analysis and modeling of mechanisms for regulating market processes in the housing sector. Moscow: CEMI RAS.

Knight, F.H. (1921). Risk, Uncertain and Profit. New York: Houghton Mifflin Publ.

Knight, J. (2002). Listing price, time on market, and ultimate selling price: causes and effects of listing price changes. Real Estate Economics, 30(2), 213-237. 
Konstantinovsky, S. (2000). Development and regulation of the real estate market. Moscow University Economics Bulletin, $1,8-10$.

Kornilova, I. (2000). Modeling of real estate valuation in a large city. Thesis for the degree of candidate of economic sciences, St. Petersburg.

Maleeva, T. (2013). Modern directions and methods of studying the demand for services in the sphere of housing. European Social Science Journal, 4 (32), 436-444.

Maleeva, T., Selyutina, L. (2018). Analysis and evaluation of financial resources of social housing construction in city, Materials Science Forum, 931, 1118-1121.

Markowitz, H.M. (1987). Mean-Variance Analysis in Portfolio Choice and Capital. New York: Jolin Wiley Publ.

Merton, R. (1969). Lifetime portfolio selection under uncertainty: the continuous - time case. Review of Economic and Statistics, 51, 247-257.

Murphy, A. (2018). A dynamic model of housing supply. American economic journal: economic policy, 10(4), 243-267.

Pasechnyuk, N. (2014). Simulazione di sistemi di controllo processi di investimento in riproduzione di custodia. Italian Science Review, 5(14), 316-320.

Phang, S., Kim, K. \& Wachter, S. (2010). Supply Elasticity of Housing. In: International encyclopedia of housing and home, Elsevier and Science Direct.

Pyankova, I. (1997). Formation of the regional housing market. Thesis for the degree of candidate of economic sciences, St. Petersburg.

Rakova, V.A., Chalenko, A.V. \& Sheremetev, A.V. (2015). The state's participation in solving housing problem of citizens in modern conditions. Fundamental research, 12 (4), 823-827.

Selyutina, L. (2018). Innovative approach to managerial decision-making in construction business. Materials Science Forum, 931, 1113-1117.

Sidorovykh, A. (2015). Estimation of effects of transport accessibility on housing prices. Applied Econometrics, 1(37), 4356.

Sinai, T. (2010). Feedback between real estate and urban economics. Journal of Regional Science, 1(50), 423-448.

Vasileva, N. (2003). Development of housing fund's reproduction forms: a terminological aspect of the problem. Journal of the news of higher educational institutions. Construction, 1_(529), 114-118.

Wu, J., Deng, Y. \& Liu, H. (2014). House price index construction in the nascent housing market: the case of China. The Journal of Real Estate Finance and Economics, 48, 522-545.

Yishen, L. (2018). Estimating the elasticity of supply of housing space rather than units. Regional Science and Urban Economics, 68, 1-10. 